\title{
Pengenalan Konsep Asta Kosala-Kosali Pada Bade Di Bali Berbasis Multimedia Interaktif
}

\author{
I Dewa Gede Agung Pandawana ${ }^{* 1}$, Ida Bagus Gede Mertha Sedhana ${ }^{2}$ \\ ${ }^{* 1}$ Program Studi Manajemen Universitas Mahasaraswati Indonesia \\ ${ }^{2}$ Teknik Informatika, STMIK STIKOM Indonesia, Bali, Indonesia \\ e-mail: *11 pandawana@unmas.ac.id, ${ }^{2}$ Bagusmertha12@gmail.com
}

\begin{abstract}
Abstrak
Asta Kosala Kosali merupakan salah satu materi lokal khas Bali dalam pelajaran bangunan adat Bali. Asta Kosala Kosali juga digunakan dalam konsep pembuatan Bade, dimana konsep pengukuran Bade didasari oleh pengukuran yang terdapat dalam Asta Kosala Kosali. Seiring perkembangan jaman, masih banyak masyarakat yang tidak tahu ataupun paham mengenai aturan Asta Kosala Kosali, sehingga pakem bangunan khas Bali sedikit demi sedikit akan berkurang di masa mendatang. Oleh karena itu media informasi pembelajaran interaktif dapat membantu masyarakat dalam proses penyampaian materi yang dirasa sangat dibutuhkan dan sebagai media penunjang untuk materi Asta Kosala Kosali dan Bade.

Dalam pembuatan media interaktif ini penulis menggunakan software Coreldraw X7 untuk pembuatan karakter yang ada didalam media pembelajaran, kemudian untuk proses animasi, pembuatan tombol, dan pemberian backsound dilakukan menggunakan aplikasi Adobe Flash CS 6.

Media Informasi ini telah diujikan dengan penyebaran kuesioner ke masyarakat sebanyak 30 orang, dengan tujuan untuk mengetahui seberapa layak aplikasi ini dapat digunakan. Dari hasil kuesioner yang telah dibagikan diperoleh bahwa 97\% masyarakat menyatakan sangat baik dengan adanya media informasi pengenalan Bade di Bali berbasis multimedia interaktif ini sebagai media informasi pembelajaran.
\end{abstract}

Kata kunci-Asta Kosala Kosali, Bade, Multimedia, Interaktif, Bali

\section{Abstract}

Asta Kosala Kosali is one of the Balinese local materials in Balinese traditional building lessons. Asta Kosala Kosali is also used in the concept of making Bade, where the concept of measuring Bade is based on the measurements contained in Asta Kosala Kosali. As time goes by, there are still many people who do not know or understand the rules of Asta Kosala Kosali, so the standard Balinese building will gradually diminish in the future. Therefore interactive learning information media can help the community in the process of delivering material that is deemed indispensable and as a supporting medium for Asta Kosala Kosali and Bade materials.

In making this interactive media the writer uses Coreldraw X7 software for character creation in the learning media, then for the animation process, button creation, and backsound giving is done using the Adobe Flash CS 6 application.

This information media has been tested by distributing questionnaires to the community as many as 30 people, with the aim of finding out how feasible this application can be used. From the results of the questionnaires that have been distributed, it was found that $97 \%$ of the 
people stated that it was very good with the introduction of information media for the introduction of Bade in Bali based on interactive multimedia as a learning information medium.

Keywords-Asta Kosala Kosali, Bade, Multimedia, Interactive, Bali

\section{PENDAHULUAN}

$\mathrm{B}$ ali merupakan pulau yang dikenal dengan sebutan pulau dewata dan salah satu pulau yang merupakan surga wisata. Bali memiliki daya tarik berwisata baik untuk wisatawan asing maupun wisatawan lokal, karena daerahnya memiliki keindahan yang sangat menarik bagi para wisatawan. Tidak hanya keindahan daerahnya saja yang menarik wisatawan namun juga keaneka ragaman kesenian serta kebudayaan yang ada di Balipun menarik untuk dikenal lebih jauh oleh para wisatawan. Bali juga memiliki banyak warisan budaya dari leluhur yang masih tertanam dan melekat erat pada kebiasaan dalam kehidupan masyarakat Bali itu sendiri. Selain warisan budaya, Bali juga memiliki berbagai tradisi unik yang masih dipegang teguh, dilaksanakan dan terjaga baik di kalangan masyarakat. Budaya dan tradisi tersebut memiliki ciri khas tersendiri pada masing-masing daerah, desa maupun banjar yang ada di Bali.

Adat istiadat seperti upacara agama, seni tari, seni musik, termasuk bangunan khas Bali sangat erat hubungannya satu sama lain. Berbicara tentang bangunan adat khas Bali, tidak terlepas dari aturan bernama Asta Kosala Kosali. Asta Kosala Kosali sangat identik dengan kebudayaan pembangunan di Bali. Dari sekian banyak bangunan pelinggih dan seni bangun Bali lainnya pasti menggunakan prinsip Asta Kosala Kosali. Seperti terlihat pada Pura Besakih yang mengunakan prinsip tradisional Agama Hindu untuk pembangunannya. Selain itu Asta Kosala Kosali juga digunakan dalam konsep pembuatan Bade, ini didasari berdasarkan wawancara yang saya lakukan kepada Bapak Ida Bagus Nyoman Parsa selaku undagi bade di Desa Angantaka. Beliau mengatakan bahwa konsep pengukuran Bade didasari oleh pengukuran yang terdapat dalam Asta Kosala Kosali, namun yang menjadi patokan adalah tangannya Dewa Siwa. Tangan Dewa Siwa bersifat maha besar dan maha kecil sehingga tidak salah jika pengukuran pembuatan Bade berbeda antara undagi satu dengan undagi yang lain.

Asta Kosala Kosali adalah ilmu seni bangun Hindu, dimana dalam Asta Kosala Kosali terdapat aturan tentang tata cara, tata letak, dan tata bangunan untuk tempat tinggal serta bangunan tempat suci yang ada di Bali. Bangunan yang dibangun sesuai dengan landasan Filosofis, Etis, dan Ritual dengan memperhatikan konsepsi perwujudan, pemilihan lahan, hari baik (dewasa) membangun rumah, serta pelaksanaan yadnya. Disamping itu Asta Kosala Kosali memiliki kegunaan untuk penangkal kekuatan jahat (penolak bala) agar orang yang bertempat tinggal di rumah tersebut memperoleh kedamaian sejahtera secara rohani. Asta Kosala Kosali ini bertujuan untuk memperoleh kesejahteraan dan kedamaian, mendapat vibrasi kesucian serta menguatkan bhakti kepada Ida Sang Hyang Widhi Wasa.

Seiring perkembangan jaman, masih banyak masyarakat yang tidak tahu ataupun paham mengenai aturan Asta Kosala Kosali. Padahal Asta Kosala Kosali ini sangat berguna bagi kehidupan masyarakat Bali itu sendiri. Karena jika masyarakat mengesampingkan aturan Asta Kosala Kosali ini biasanya terjadi dalam sifat spiritual yaitu tidak betah dalam rumah karena pekarangan rumah terasa panas (leteh), sering terjadinya gangguan-gangguan dari pihak lain, tidak mendapatkan kesejahteraan dan kedamaian secara rohani. Selain itu, minimnya media informasi yang menjelaskan pengertian serta pentingnya Asta Kosala Kosali tersebut, membuat hanya segelintir masyarakat yang mengetahui tentang Asta Kosala Kosali. Hal itu berdampak pada generasi sekarang yang akan mewarisi generasi selanjutnya, mereka tidak mengenal aturan Asta Kosala Kosali sehingga pakem bangunan khas Bali sedikit demi sedikit akan berkurang di masa mendatang.

Dunia pendidikan sangat berperan besar dalam hal meningkatkan taraf pendidikan serta

JSIKTI Vol. 2, No. 3, July 2020 : 
pengetahuan dari seluruh masyarakat di masa depan. Untuk menambah pengetahuan serta pemahaman masyarakat tentang seni bangun Hindu ini, sudah sepantasnya pengetahuan tentang Asta Kosala Kosali ini diperkenalkan sejak dini. Untuk memfasilitasi hal tersebut, media informasi interaktif dapat digunakan untuk membantu pengenalan tentang Asta Kosala Kosali di dunia pendidikan. Media interaktif dipilih karena dapat membuat proses pembelajaran lebih menarik dengan gambar-gambar ilustrasi cerita, suara, dan teks dapat terintegrasi dan dapat dikendalikan sesuai keinginan. Hal ini dapat membuat masyarakat lebih tertarik untuk belajar tentang ciri khas Bali dan lebih mudah untuk mencerna serta memahami materinya. Pemakaian media pembelajaran dalam proses belajar mengajar juga dapat membangkitkan keinginan dan minat yang baru bagi masyarakat, serta membangkitkan motivasi belajar masyarakat.

Berdasarkan pemaparan latar belakang maka judul dari laporan tugas akhir adalah "Media Informasi Pengenalan Bade di Bali Berbasis Multimedia Interakif". Diharapkan, dengan adanya media interaktif ini dapat membantu masyarakat untuk mengetahui tentang Asta Kosala Kosali dan Bade sejak dini melalui media interaktif.

\section{METODE PENELITIAN}

Metode penelitian meliputi analisa permasalahan, arsitektur atau rancangan metode yang digunakan untuk menyelesaikan Sistem Informasi Pemesanan Tiket Permainan Wisata Bahari.

\subsection{Asta Kosala Kosali}

Menurut Bidja $(2000,3)$ Asta Kosala adalah nama lontar/buku tentang ukuran membuat menara atau bangunan tinggi, wadah, bade, usungan mayat. Asta Bumi (Kosali) adalah nama lontar/buku tentang ukuran membuat rumah dan bangunan suci.

Menurut Atmanadhi $(1975,2)$ Asta Kosala Kosali merupakan sebuah cara penataan lahan untuk tempat tinggal dan bangunan suci. Penataan Bangunan biasanya menggunakan anatomi tubuh manusia. Pengukuran didasarkan pada ukuran tubuh, tidak menggunakan meter.

Menurut Atmanadhi $(1975,4)$ konsep penataan Rumah di Bali juga didasarkan oleh Buana Agung (Makrokosmos) dan Buana Alit (Mikrokosmos). Yaitu sebagai berikut :

1. Bhur, alam nista yang menjadi simbolis keberadaan setan dan nafsu yang selalu menggoda manusia untuk berbuat menyimpang dari dharma.alam semesta.

2. Bwah, alam manusia dan kehidupan keseharian yang penuh dengan godaan duniawi, yang berhubungan dengan materialisme.

3. Swah, Sorga alam dewa-dewi dan Brahman, alam yang dihuni oleh jiwa-jiwa (atman) yang bathinnya bersih dan suci serta hidupnya penuh welas asih dan dharma kebaikan.

4. Selain itu, Asta Kosala Kosali juga berpatokan pada Nawa Sanga (9 mata angin). Setiap bangunan itu memiliki tempat sendiri. Yaitu sebagai berikut :

a. Dapur, karena berhubungan dengan Api maka Dapur ditempatkan di Selatan (Dewa Brahma).

b. Tempat Sembahyang karena berhubungan dengan menyembah akan di tempatkan di Timur tempat matahari Terbit (Dewa Surya).

c. Karena Sumur menjadi sumber Air maka ditempatkan di Utara dimana Gunung berada (Dewa Wisnu).

Dalam upacara pitra yadnya, bade dan wadah merupakan sarana yang penting tetapi tidak harus mutlak ada. Menurut I Putu Gede Suyoga (2014) dalam bukunya "Arsitektur Bade, Transformasi Konsep Menuju Bentuk", bade atau wadah boleh dan penting dibuat serta digunakan, tetapi bukanlah esensial. Artinya, tanpa bade pun upacara pitra yadnya pengabenan sudah bisa disebut sah.

Penekun lontar sekaligus undagi bade asal Angantaka Ida Bagus Nyoman Parsa mengatakan bade dan wadah merupakan simbol dari sukuning (bagian bawah) dari Gunung Maliawan. Bade atau wadah memiliki fungsi sama sebagai saana pemberangkatan jenazah ke 
setra dalam upacara pitra yadnya. Namun secara fisik, kedua sarana itu sebetulnya memili perbedaan. Ditegaskan, jika menggunakan tumpang (atapnya bertingkat) disebut bade, sedangkan yang tidak bertumpang disebut wadah. Namun, wadah bisa disebut bade jika menggunakan palih bade seperti bacem, batur, taman, sari.

Selain berbentuk bade dan wadah, ada juga sarana pitra yadnya yang bisa disebut bade namun bentuknya sedikit berbeda, yakni balai pebasmian. Bentuknya seperti bangunan balai yang di dalamnya berisi bale kantil tempat jenazah, dilengkapi dengan pepalihan seperti boma bersayap, macam-macam kekarangan, kekitir, dan brapakat. Jika dikaitkan dengan catur warna dalam konsep profesi golongan manusia di Bali, ada aturan khusus penggunaan bade. Misalnya, keturunan mana saja yang boleh menggunakan bade bertumpang solas (11), sanga (9), pitu (7), lima (5) dan seterusnya.

Wadah sesungguhnya adalah karya nyata sebuah kewajiban manusia secara langsung turun tangan ikut bertanggung jawab terhadap kelestarian alam ( Bhuana Agung dan Bhuana Alit ) secara timbal balik, nantinya alam akan memberikan kesejahteraan kepada manusia secara otomatis. Lambang - lambang yang digambarkan dalam sarana wadah sebenarnya member arah yang jelas kepada manusia bagaimana dan kemana arah tujuan hidup, khususnya konsep pengelolaan hidup menuju kebahagiaan sekala dan niskala.

\subsection{Arsitektur Bade di Bali}

Pemakaian bade juga sangat dipengaruhi kemampuan ekonomi dan besar kecilnya tingkat pelaksanaan upacara pengabenan/pelebon yang akan dilaksanakan. Klasifikasi tinggi rendahnya tingkatan upacara dibagi menjadi tiga tingkat menurut Suyoga $(2014,39)$, yaitu sebagai berikut:

1. Bade Tingkat Nista (Sederhana), dibagi menjadi tiga yakni :

a) Nistaning Nista (Tingkat paling sederhana)

b) Madyaning Nista (Tingkat sederhana yang menengah)

c) Utamaning Nista (Tingkat sederhana yang tertinggi)

2. Bade Tingkat Madya (Menengah), dibagi menjadi tiga yakni :

a) Nistaning Madya (Tingkat menengah yang sederhana)

b) Madyaning Madya (Tingkat menengah yang sedang)

c) Utamaning Madya (Tingkat menengah yang tertinggi)

3. Bade Tingkat Utama (Utama), dibagi menjadi tiga yakni :

a) Nistaning Utama (Tingkat utama yang paling rendah)

b) Madyaning Utama (Tingkat utama yang menengah)

c) Utamaning Utama (Tingkat utama yang tertinggi)

Selain itu menurut Suyoga $(2014,24)$ arsitektur bade juga dipengaruhi berdasarkan strata sosial tradisional masyarakat Bali. Jenis bade atau wadah dapat dibagi berdasarkan bentuk dan kelompok social yang menggunakan soroh/klan orang yang diaben. Jenis wadah berdasarkan bentuknya ada empat jenis yaitu: Padma, bade, joli dan pepaga. Sedangkan jenis wadah berdasarkan kelompok sosialnya ada empat yaitu: kelompok brahmana, ksatriya, waisya, dan sudra.

Seni Yang Terdapat Dalam Wadah/Bade pada Upacara Pitra Yadnya, Ornamen wadah adalah hiasan yang menempel atau berada menjadi satu kesatuan pada suatu bangunan wadah. Secara umum ornamen - ornamen yang dipergunakan pada wadah dalam upacara Pitra Yadnya meliputi :
a) Karang Gajah
b) Karang Sari
c) Karang Guak
d) Garuda
e) Bhoma
f) Wilmana

JSIKTI Vol. 2, No. 3, July 2020 : 


\subsection{Multimedia}

Menurut Suyanto (dalam Novitasari, 2010, 22), Multimedia adalah kombinasi dari computer dan video atau multimedia secara umum merupakan kombinasi tiga elemen yaitu : suara, gambar, dan teks atau multimedia adalah kombinasi dari paling sedikit 2 media input atau output dari data, media ini dapat berupa audio (suara, music),animasi, video, teks, grafik dan gambar atau multimedia merupakan alat yang menciptakan presentasi yang dinamis dan interaktif yang mengkombinasikan teks, grafik, animasi, audio dan gambar video

Menurut Robin dan Linda (dalam Novitasari, 2010, 22), Multimedia adalah pemanfaatan komputer untuk membuat dan menggabungkan teks, grafik, audio, video dan animasi denganmenggabungkan link dan tool yang memungkinkan pengguna melakukan navigasi, berinteraksi, berkreasi dan berkomunikasi. Dalam definisi ini terkandung empat komponen penting multimedia. Pertama, harus ada Komputer yang mengkoordinasikan apa yang dilihat dan didengar, yang berinteraksi dengan pengguna. Kedua, harus ada link yang menghubungkan pengguna dengan informasi. Ketiga, harus ada alat navigasi yang memadu pengguna, menjelajah jaringan informasi yang saling terhubung. Keempat, multimedia menyediakan tempat kepada pengguna untuk mengumpulkan, memproses, dan mengkomunikasikan informasi dan ide sendiri. Jika salah satu komponen tidak ada, maka bukan multimedia dalam arti yang luas namanya. Misalnya, jika tidak ada computer untuk berinteraksi, maka itu namanya media campuran, bukan multimedia. Jika ada link yang menghadirkan sebuah struktur dan dimensi, maka namanya rak buku, bukan multimedia. Kalau tidak ada alat navigasi yang memungkinkan pengguna memilih jalannya suatu tindakan maka itu namanya film, bukan multimedia.Demikian juga jika pengguna tidak mempunyai ruang untuk beekreasi dan menyumbangkan ide sendiri, maka namanya televise, bukan multimedia. Dari beberapa definisi diatas, maka multimedia ada yang online (internet) dan multimedia yang offline (tradisional).

Sedangkan Hofstetter (dalam Suyanto, 2005, 21), menyatakan, multimedia adalah pemanfaatan komputer untuk membuat dan menggabungkan teks , grafik, audio, gambar bergerak (video dan animasi) dengan menggabungkan link dan tools, yang memungkinkan pemakai melakukan navigasi, berinteraksi, berkreasi dan berkomunikasi.

Multimedia Interaktif, Menurut Seels dan Glasgow dalam Arsyad (2006, 36) mengemukakan bahwa media interaktif merupakan sistem media penyampaian yang menyajikan materi video rekaman dengan pengendalian computer kepada penonton yang tidak hanya mendengar dan melihat video dan suara, tetapi juga memberikan respon yang aktif dan respon itu yang menentukan kecepatan dan sekuensi penyajian. Media interaktif memiliki unsur audio-visual (termasuk animasi) dan disebut interaktif karena media ini dirancang dengan melibatkan respon pemakai secara aktif. Selain itu menurut Kamus Besar Bahasa Indonesia (KBBI) media interaktif adalah alat perantara atau penghubung berkaitan dengan komputer yang bersifat saling melakukan aksi antar-hubungan dan saling aktif. Dari definisi diatas dapat diambil kesimpulan bahwa media interaktif adalah alat perantara yang dirancang dengan pemanfaatan komputer menggunakan unsur seperti suara (audio), gambar (visual) dan teks untuk menyampaikan suatu pesan.

\subsection{Warna}

Menurut Nugroho $(2008,35)$, warna diyakini mempunyai dampak psikologis terhadap manusia. Dampak tersebut dapat dipandang dari berbagai maram aspek, baik aspek panca indra, aspek budaya, dan lain-lain. Adapun Rasa Terhadap Warna

1. Warna Netral, adalah warna-warna yang tidak lagi memiliki kemurnian warna atau dengan kata lain bukan merupakan warna primer maupun sekunder. Warna ini merupakan campuran ketiga komponen warna sekaligus, tetapi tidak dalam komposisi tepat sama.

2. Warna Kontras, adalah warna yang berkesan berlawanan satu dengan lainnya. Warna kontras bias didapatkan dari warna yang berseberangan (memotong titik tengah segitiga) terdiri atas 
warna primer dan warna sekunder. Tetapi, tidak menutup kemungkinan pula membentuk kontras warna dengan mengolah nilai ataupun kemurnian warna. Contoh warna kontras adalah merah dengan hijau, kuning dengan ungu, dan biru dengan jingga.

3. Warna panas, adalah kelompok warna dalam rentang setengah lingkaran di dalam lingkaran warna mulai dari merah hingga kuning. Warna ini menjadi symbol, riang, semangat, merah, dan lain-lain. Warna panas mengesankan jarak yang dekat. Tetapi justru barang yang mempunyai warna panas ini radiasi panasnya kecil.

4. Warna dingin, adalah kelompok warna dalam rentang setengah lingkaran di dalam lingkaran warna mulai dari hijau hingga ungu. Warna ini menjadi symbol kelembutan, sejuk, nyaman, dan sebagainya. Warna sejuk mengesankan jarak yang jauh. Tetapi justru barang yang mempunyai warna dingin ini radiasi panasnya besar.

\subsection{Story Board}

Storyboard dari media pembelajaran yang dibuat antara lain:

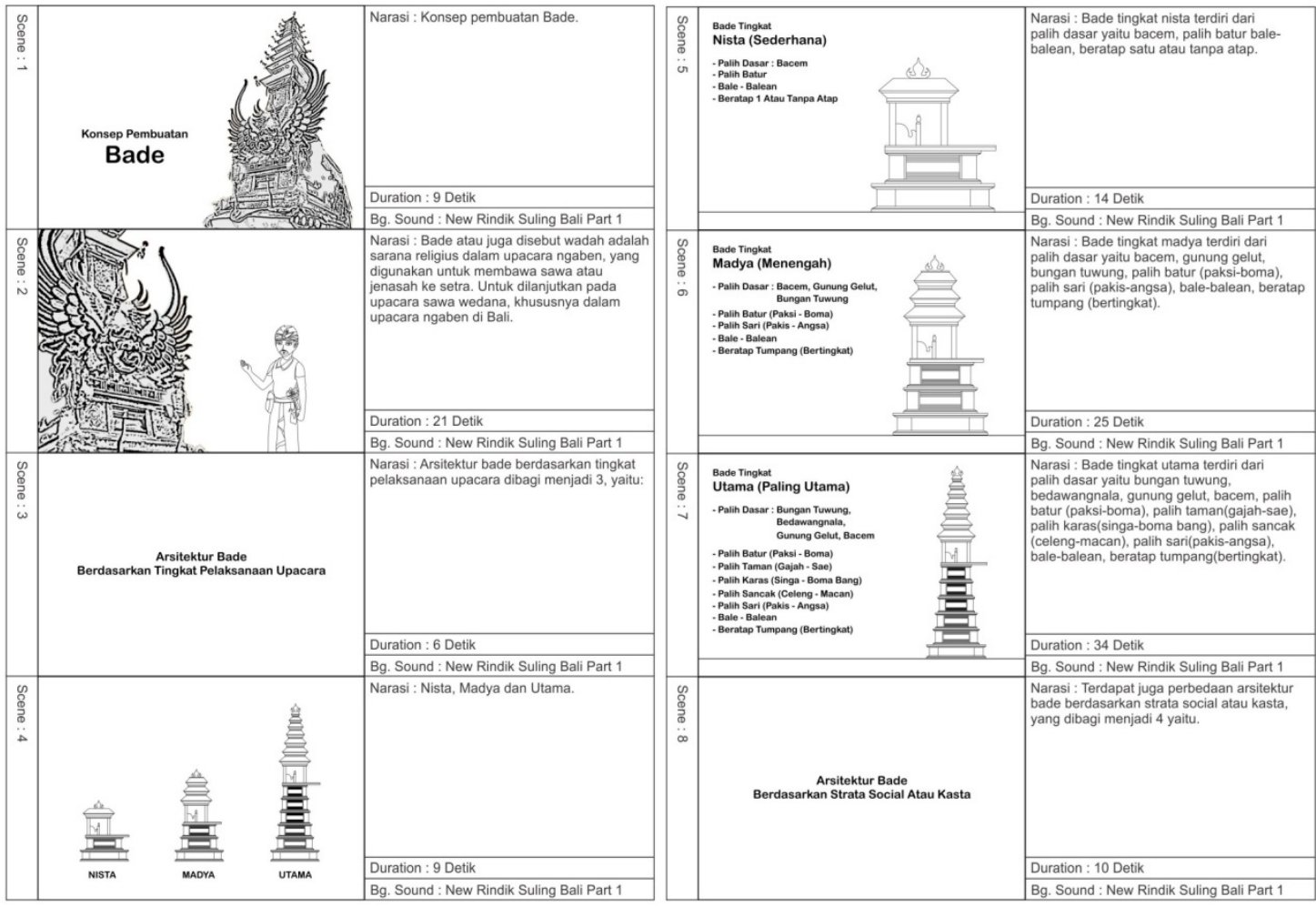

Gambar 1 Storyboard media pembelajaran

\section{HASIL DAN PEMBAHASAN}

Dalam implementasi sistem ini menerangkan fungsi form-form yang ada dalam Aplikasi Reservasi. Berikut ini adalah implementasi sistem yang sudah dibuat:

\subsection{Implementasi Menu Pembuka}

Halaman intro adalah tampilan yang pertama muncul ketika membuka interaktif multimedia akan menampilkan karakter orang tua durasi $5 \mathrm{~s}$. Terdapat tombol masuk untuk kemenu utama. Untuk tampilan Halaman into dapat dilihat pada Gambar 2. Pada menu utama terdapat empat buah tombol, yaitu tombol "materi", "petunjuk", "profil" dan "tentang aplikasi"

JSIKTI Vol. 2, No. 3, July 2020 : 
masing-masing tombol akan menuju halaman materi, petunjuk, profil dan tentang aplikasi. Untuk tampilan menu utama dapat dilihat pada Gambar 3.

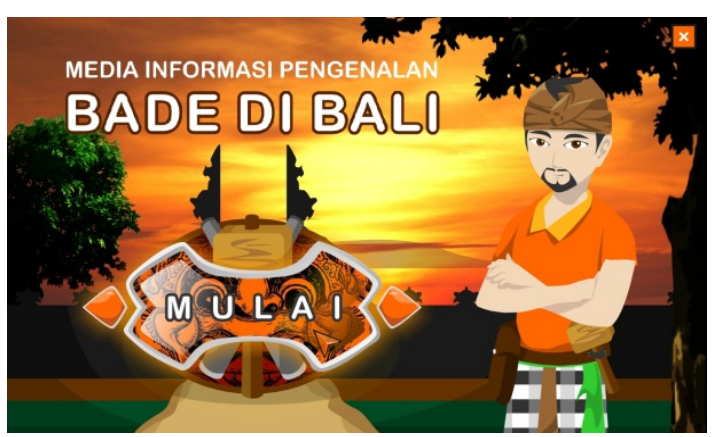

Gambar 2 Halaman Intro

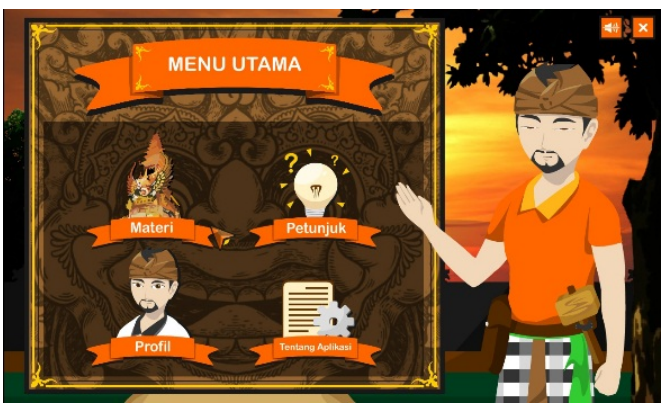

Gambar 3 Menu Utama

Halaman ini menampilkan materi yang akan dipilih dimana dalam halaman materi terdapat tiga buah tombol yaitu "pengertian", "fungsi" dan "bade". Untuk lebih jelasnya dapat dilihat pada Gambar 4.

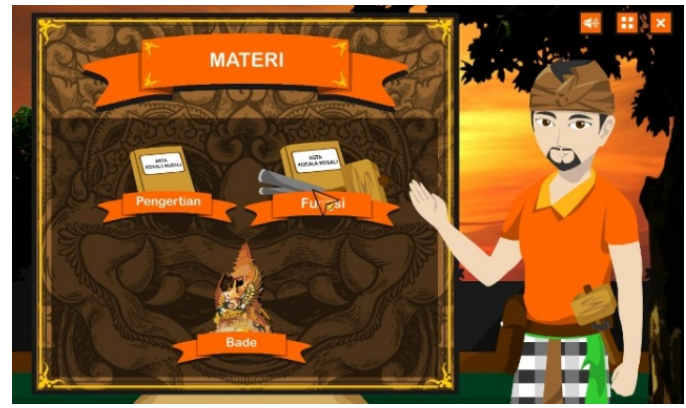

Gambar 4 Halaman Materi

\subsection{Implementasi Menu Permainan}

Pada Halaman Materi Pengertian Pada halaman ini ditampilkan penjelasan dilengkap mengenai pengertian Asta Kosala Kosali. Untuk lebih jelasnya dapat dilihat pada Gambar 5.

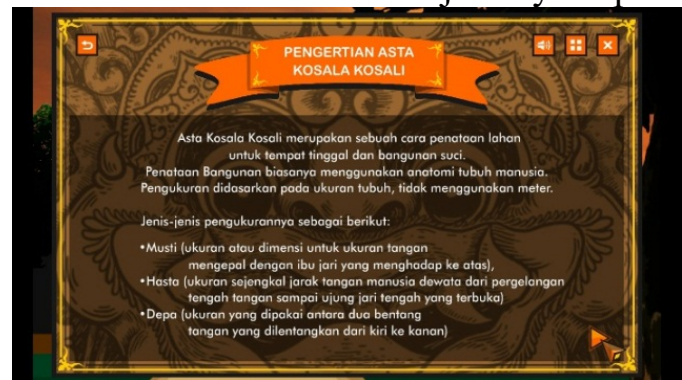

Gambar 5 Halaman Materi pengertian 
Halaman Materi Bade terdapat tiga buah tombol, yaitu tombol "fungsi bade", "gambar", dan "animasi" masing-masing tombol akan menuju halaman fungsi bade, gambar dan animasi ditampilkan penjelasan tentang Bade. Untuk lebih jelasnya dapat dilihat pada Gambar 6.

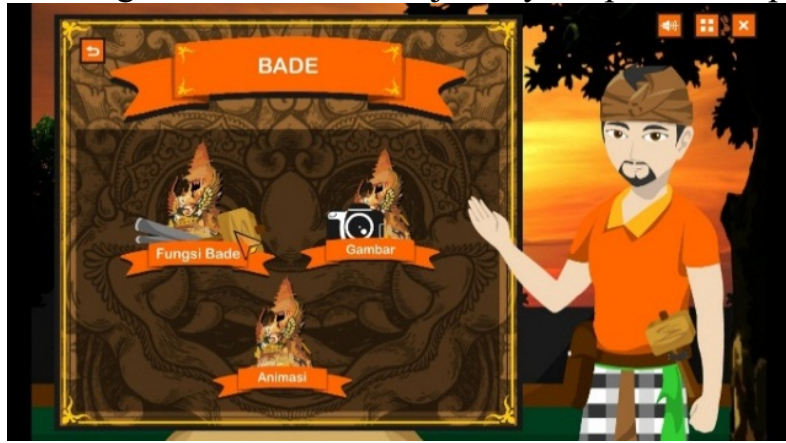

Gambar 6 Materi Bade

Halaman Petunjuk ditampilkan petunjuk penggunaan aplikasi. Untuk lebih jelasnya bisa dilihat pada Gambar 7.

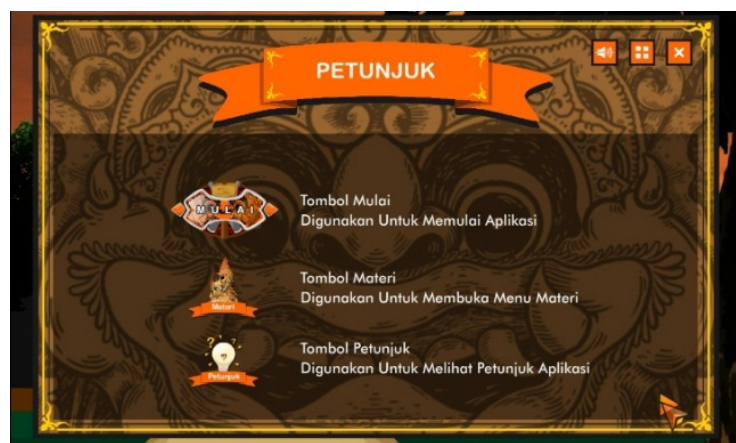

Gambar 7 Petunjuk

Halaman Tentang Aplikasi, Pada halaman ini ditampilkan tentang aplikasi. Untuk lebih jelasnya bisa dilihat pada Gambar 8 .

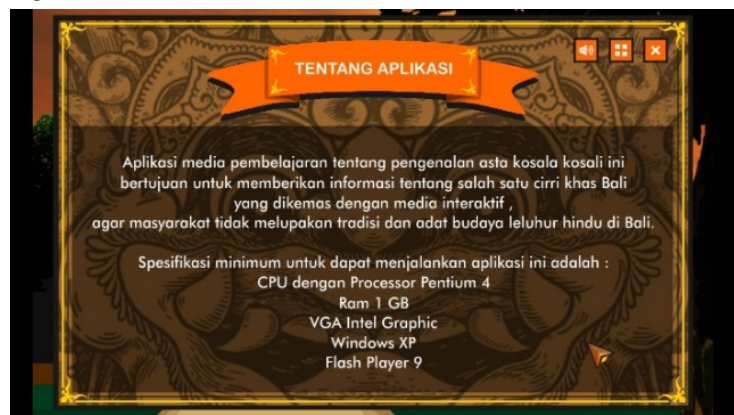

Gambar 8 Tentang Aplikasi

Halaman Profil, Pada halaman ini ditampilkan profil pembuat aplikasi. Untuk lebih jelasnya bisa dilihat pada Gambar 9 .

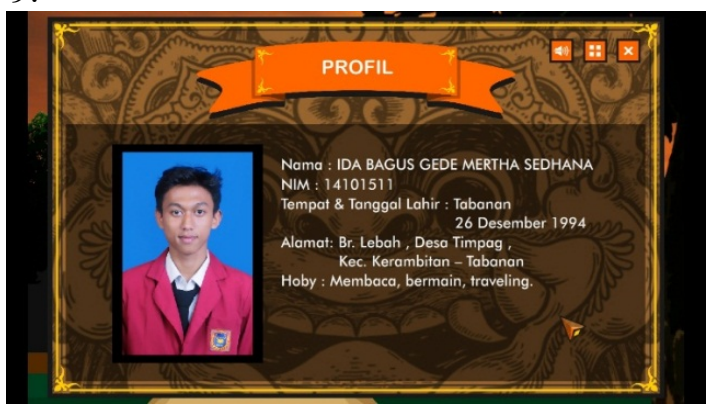

Gambar 9 Profil

JSIKTI Vol. 2, No. 3, July 2020 : 


\section{KESIMPULAN}

Kesimpulan yang dapat diambil dalam perancangan sistem informasi yang dilakukan adalah sebagai berikut, Proses perancangan multimedia interaktif tentang pengenalan Bade di Bali dilakukan melalui tahapan pra produksi yaitu menentukan konsep, melakukan riset, membuat skenario, layout, dan terakhir adalah membuat aset. Tahap produksi yaitu penyusunan animasi sesuai alur menu yang sudah dibuat dan pasca produksi yaitu import gambar, import suara, dan setelah semua komponen sudah lengkap, maka langkah terakhir adalah Publish menjadi ekstensi *.exe. Berdasarkan hasil pengujian kuesioner terhadap masyarakat yang dipilih secara acak dapat disimpulkan bahwa 97\% masyarakat sangat setuju pada aplikasi multimedia interaktif tentang pengenalan Bade di Bali ini. Maka keseluruhan hasil pengujian ini menunjukkan seluruh masyarakat memberikan tanggapan yang baik.

\section{DAFTAR PUSTAKA}

[1] Aging. 2015. Rancang Bangun Multimedia Interaktif Untuk Pengenalan Kerajaankerajaan Hindu-Budha Di Indonesia. Denpasar: STMIK STIKOM INDONESIA.

[2] Ali, Mat. 2014. Mahir Software Desain Grafis. Jakarta: Techno Publishing

[3] Arikunto, Suharsimi. 2010. Prosedur Penelitian: Suatu Pendekatan

[4] Praktik. Jakarta: Rineka Cipta

[5] Arsyad. 2006. Media Pembelajaran. Jakarta: Raja Grafindo Persada

[6] Atmanadhi, I.N.S. 1975. Asta Kosala Kosali Gumi Bhagawan Swakarma. Jakarta: Percetakan Aksara.

[7] Bidja, I Made. 2000. Asta Kosala Kosali Asta Bumi. Bali: Pustaka Bali Post

[8] Bovee, Courland. 1997. Business Communication Today. New York: Prentice Hall.

[9] Darwini, Gusti Ayu. 2008. Wadah Dalam Upacara Ngaben Ngerit di Desa Takmung. Kecamatan Banjarangkan, Kabupaten Bangli.

[10] Hurst, Ken. 2006. Prinsip - prinsip perancangan teknik. Jakarta: Erlangga

[11] Jogiyanto. 2008. Metodologi Penelitian Sistem Informasi. Yogyakarta: CV Andi Offset.

[12] Krisnadi. 2004. Pemanfaatan Program CAI sebagai Sarana untuk Membantu siswa dalam Menyerap konsep-konsep Matematika dengan pendekatan Abstrakkonkret. Jakarta: Pustekkom

[13] Kusrianto, Adi. 2009. Pengantar Desain Komunikasi Visual. Yogyakarta: ANDI.

[14] Ladjamudin. 2005. Analisis dan Desain Sistem Informasi. Yogyakarta : Graha Ilmu.

[15] Nawawi. 1998. Metode Penelitian Bidang Sosial. Yogyakarta: Gadjah

[16] Nazir. 1998. Metode Penelitian. Jakarta: Ghalia Indonesia.

[17] Nugroho, Bunafit. 2008. Aplikasi Pemrograman Web Dinamis Dengan PHP dan MySQL. Yogyakarta: Gava Media.

[18] Nurina, Purnami Dewi. 2017. Media Pembelajaran IPA Pengenalan Organ Peredaran Darah Pada Manusia Berbasis Multimedia Interaktif Untuk Kelas V Di SD Islam Tabanan. Denpasar: STMIK STIKOM INDONESIA.

[19] Patmore, Chris. 2003. The Complete Animation Course. United Kingdom: Thames And Hudson.

[20] Poerwadarminta. 1985. Kamus Umum Bahasa Indonesia. Jakarta: Balai Pustaka. Pramono.

[21] Pujiriyanto. 2005. Desain Grafis Komputer. Yogyakarta: Andi.

[22] Rustan, Surianto. 2010. Font \& Tipografi. Jakarta : PT Gramedia

[23] Pustaka Utama

[24] Safanayong, Yongky. 2006. Desain komunikasi visual Terpadu. Jakarta: ARTE INTERMEDIA. 
[25] Santyasa, I Wayan. 2007. Landasan Konseptual Media Pembelajaran. Jakarta: PT. Gramedia Pustaka Utama

[26] Sanyoto, Sadjiman Ebdi. 2009. Nirmana Elemen-Elemen Seni dan

[27] Desain. Yogyakarta : Jalasutra.

[28] Sevilla, dkk. 1993. Pengantar Metodologi Penelitian. Jakarta: Universitas. Indonesia

[29] Soebandi, Ketut. 2001. Babad Pasek. Denpasar: Yayasan Adhi Sapta Kerthi.

[30] Sugiyono. 2011. Metode penelitian kuntitatif kualitatif dan R\&D. Bandung: Alfabeta

[31] Sumanto. 2014. Teori dan Aplikasi Metode Penelitian. Yogyakarta : CAPS.

[32] Supriyono, Rakhmat. 2010. Desain Komunikasi Visual Teori dan

[33] Aplikasi. Yogyakarta: Andi Offset

[34] Suyoga, I Putu Gede. 2014. Arsitektur Bade, Transformasi Menuju Bentuk. Ubud: Yayasan Kryasta Guna

[35] Uma, Sekaran. 2006. Metodologi Penelitian Untuk Bisnis, Edisi Keempat. Jakarta: Penerbit Salemba

[36] Wahyuni, E. N. 2008. Teori Belajar dan Pembelajaran. Yogyakarta: Ar-ruzz media 